\title{
Reel syndrome: a rare cause of pacemaker malfunction
}

\author{
Luis Alvarez-Acosta, Rafael Romero Garrido, Marcos Farrais-Villalba, \\ Julio Hernández Afonso
}

Department of Cardiology, Hospital Universitario Nuestra Señora de la Candelaria, Santa Cruz de Tenerife, Santa Cruz de Tenerife, Spain

\section{Correspondence to}

Luis Alvarez-Acosta, luisalvaco@gmail.com

Accepted 26 April 2014

\section{CrossMark}

\footnotetext{
To cite: Alvarez-Acosta $L$, Romero Garrido R, FarraisVillalba M, et al. BMJ Case Rep Published online: [please include Day Month Year] doi:10.1136/bcr-2014204545
}

\section{DESCRIPTION}

An 82-year-old woman was admitted to our hospital because of syncope. A 12-lead ECG demonstrated atrial fibrillation with a ventricular response of $35 \mathrm{bpm}$, and a VVIR (ventricular pacing, ventricular sensing, inhibiting mode, rate response function) pacemaker was implanted using a ventricular active fixation lead via the left subclavian artery. Prior to discharge a chest X-ray was taken and showed normal ventricular lead placement but with a minor lead retraction (figure 1A). One month after implantation she came again to the emergency room with dizziness with a ventricular response of $42 \mathrm{bpm}$. A chest X-ray was urgently performed and showed ventricular lead retraction (figure 1B, black arrow) secondary to rotation of the pulse generator on its transverse axis with subsequent coiling of the lead (figure $1 \mathrm{~B}$, white arrow). This situation has been named 'Reel Syndrome' and it happens when the generator rotates around its sagittal axis, causing the electrode to roll up like a spool above or below the generator. The patient underwent emergent ventricular lead repositioning and the pulse generator was fixed to the pectoral muscle without any further complications. We postulate that the minor lead retraction that was noticed with the first chest X-ray should have warned us about the incomplete fixation of the lead to the pectoral muscle.

Reel syndrome is a rare cause of an implantable device malfunctioning. ${ }^{1}$ It is commonly included in the macrodislocation lead-dysfunctioning syndromes along with Twiddler's and Ratchet syndromes. They differ from each other in the causing mechanism. Twiddler's syndrome is caused by retraction and dislocation of the electrodes due to rotation of the generator around the axis defined by
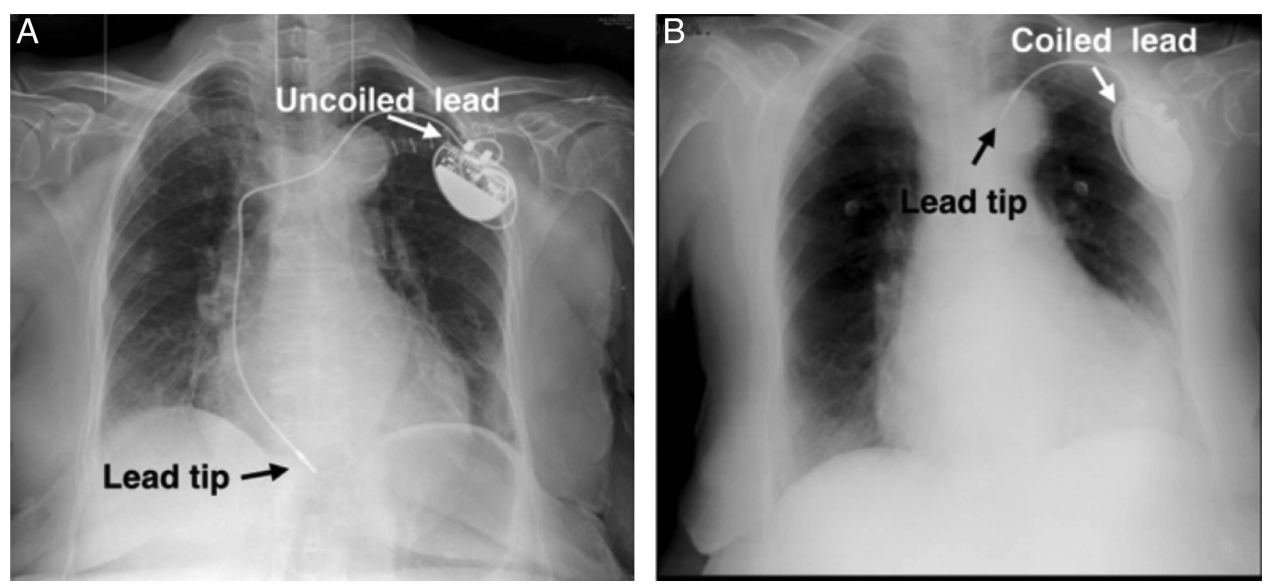

Figure 1 (A) Normal position of the ventricular lead. Black arrow pointing at the lead tip. (B) Dislocation of the lead and coiling in the pectoral pocket.

the electrode. Although an external manipulation by the patient can facilitate it, this would not be a necessary condition. Owing to this rotational movement, the electrode winds as a braid, which defines the characteristic appearance of this finding. Ratchet syndrome is caused by retraction and electrode dislocation with ratcheting but without coiling of the generator due to progressive displacement of the electrodes from their fixing protections. ${ }^{2}$ Twiddler's and Reel syndromes have similar aetiologies; female gender, large pocket, obesity, children, older people and dementia can be listed as contributing factors and their prevalence is unknown. Reel syndrome commonly occurs within a month of implantation and normally there is no damage of the leads. This is the reason why normally there is no need of lead change, unlike Twiddler's syndrome where the leads are normally damaged and their replacement is usually mandatory. ${ }^{3}$ Chest X-ray is a simpler and better method for diagnosis and therefore it is always requested when such a complication is suspected because it can easily differentiate between these three syndromes (figure 2).

\section{Learning points}

- Reel syndrome is a rare cause of pacemaker malfunction.

- Chest X-ray is mandatory in order to differentiate between lead macrodislocation syndromes.

- Lead repositioning is the elected treatment for this syndrome. 


\begin{tabular}{|c|c|c|c|}
\hline & Twiddler & Reel & Ratchet \\
\hline Mechanism & Rotation on its long axis & Rotation on its transverse axis & Retraction with ratcheting of the lead \\
\hline Consequences on Leads & Damage can occur & No damage & No damage \\
\hline X-Ray & Tangling of leads & Weads coiled around the generator \\
\hline Occurrence & Within a year & \\
\hline
\end{tabular}

Figure 2 Differences among the macrodislocation lead-dysfunctioning syndromes. PM, pacemaker; RV, right ventricle.

Contributors LÁ-A and JH-A were involved in drafting the article and gave final approval of the version to be published. RRG and MF-V contributed with the conception and design of the article and gave final approval of the version to be published.

Competing interests None.

Patient consent Obtained.

Provenance and peer review Not commissioned; externally peer reviewed.

\section{REFERENCES}

1 Carnero-Varo A, Pérez-Paredes M, Ruiz-Ros JA, et al. "Reel Syndrome": a new form of Twiddler's syndrome? Circulation 1999;100:e45-6.

2 Arias MA, Pachón M, Puchol A, et al. Terminology management for implantable cardiac electronic device lead macro-dislodgement. Rev Esp Cardiol (Engl Ed) 2012;65:671-3.

3 Nicholson WJ, Tuohy KA, Tilkemeier P. Twiddler's syndrome. N Engl J Med 2003;348:1726-7.

Copyright 2014 BMJ Publishing Group. All rights reserved. For permission to reuse any of this content visit

http://group.bmj.com/group/rights-licensing/permissions.

BMJ Case Report Fellows may re-use this article for personal use and teaching without any further permission.

Become a Fellow of BMJ Case Reports today and you can:

- Submit as many cases as you like

- Enjoy fast sympathetic peer review and rapid publication of accepted articles

- Access all the published articles

- Re-use any of the published material for personal use and teaching without further permission

For information on Institutional Fellowships contact consortiasales@bmjgroup.com

Visit casereports.bmj.com for more articles like this and to become a Fellow 